approaches have been able to reduce IL-2 toxicity or even allow administration of the intended number of IL-2 doses, let alone increase IL-2 doses.

Samlowski et al. tested M40403 in three different mouse tumor models, all different in terms of patterns of disease and sensitivity to IL-2 antitumor effects ${ }^{3}$. In none of the three tumor systems did M40403 impair IL-2 antitumor efficacy, while allowing a twofold increase in IL-2 to be administered. The reversal of IL-2-induced hypotension and increased survival was associated with elevation in circulating catecholamines.

Most impressively, in the two mouse tumor models not very sensitive to IL-2 (RENCA and MethA), IL-2 and M40403 led to a much greater antitumor effect, with long-term cures, even when combined with standard minimally effective IL-2 doses.

How does M40403 enhance IL-2 efficacy? In a small series of in vitro and in vivo experiments, M40403 seemed to enhance the IL-2-mediated generation of lymphokine-activated killer activity through an expansion of cells capable of cytolysis not restricted by major histocompatibility class. It seems that adherent macrophage populations may suppress lymphokineactivated killer activity through the production of $\mathrm{O}_{2}{ }^{\bullet-}$. Blocking $\mathrm{O}_{2}{ }^{\bullet-}$ production prevents macrophage-mediated immunosuppression. This combination may limit IL-2 toxicity while enhancing antitumor efficacy (Fig. 1).

Even now, there are other approaches that may offer the same hope, including retinoids (all-trans-retinoic acid) and inhibitors of vascular endothelial growth factor $^{11,12}$. It is clear that much work needs to be done, but translating the results of Samlowski et al. for use in cancer patients may allow others to join those few longterm survivors with advanced melanoma or renal cancer.

1. Fyfe, G. et al. Results of treatment of 255 patients with metastatic renal cell carcinoma who received high-dose recombinant interleukin-2 therapy. J. Clin. Oncol. 13, 688-696 (1995).

2. Atkins, M.B. et al. High-dose recombinant interleukin 2 therapy for patients with metastatic melanoma: analysis of 270 patients treated between 1985 and 1993. J. Clin. Oncol. 17, 2105-2116 (1999).

3. Samlowski, W.E. et al. A nonpeptidyl mimic of superoxide dismutase, M40403, inhibits doselimiting hypotension associated with interleukin-2 and increases its antitumor effects. Nat. Med. 9 , 750-755 (2003)

4. Salvemini, D. et al. A nonpeptidyl mimic of super- oxide dismutase with therapeutic activity in rats. Science 286, 304-306 (1999).

5. Macarthur, H., Westfall, T.C., Riley, D.P., Misko, T.P. \& Salvemini, D. Inactivation of catecholamines by superoxide gives new insights on the pathogenesis of septic shock. Proc. Natl. Acad. Sci. USA 97, 9753-9758 (2000).

6. Mier, J.W. \& Atkins, M.B. Mechanisms of action and toxicity of immunotherapy with cytokines. Curr. Opin. Oncol. 5, 1067-1072 (1993).

7. Hibbs, J.B. Jr. et al. Evidence for cytokineinducible nitric oxide synthesis from L-arginine in patients receiving interleukin-2 therapy. J. Clin. Invest. 89, 867-877 (1992).

8. Dubois, J. et al. Randomized placebo-controlled clinical trial of high dose interleukin-2 in combination with soluble p75 tumor necrosis factor receptor immunoglobulin $\mathrm{G}$ chimera in patients with advanced melanoma and renal cell carcinoma. J. Clin. Oncol. 15, 1052-1061 (1997).

9. McDermott, D. et al. A two-part phase I trial of high dose interleukin-2 in combination with soluble Chinese hamster ovary IL-1 receptor. Clin. Cancer Res. 5, 1203-1213 (1998).

10. Margolin, K. et al. Prospective randomized trial of lisofylline for the prevention of toxicities of highdose interleukin 2 therapy in advanced renal cancer and malignant melanoma. Clin. Cancer Res. $\mathbf{3}$, 565-572 (1997).

11. Gabrilovich, D.I., Velders, M.P., Sotomayor, E.M. \& Kast, W.M. Mechanism of immune dysfunction in cancer mediated by immature $\mathrm{Gr}-1^{+}$myeloid cells. J. Immunol. 166, 5398-5406 (2001).

12. Gabrilovich, D.I., Ishida, T., Nadaf, S., Ohm, J.E. \& Carbone, D.P. Antibodies to vascular endothelial growth factor enhance the efficacy of cancer immunotherapy by improving endogenous dendritic cell function. Clin. Cancer Res. 5, 2963-2970 (1999).

\title{
HIV hijacks dendritic cells
}

Dendritic cells take up invading pathogens and other antigens, process them and present them to T cells. In the 1 May issue of Sciencexpress, David McDonald et al. report that HIV exploits this function to infect more T cells, its primary target.

Dendritic cells take up HIV particles and gather them in protected vesicles. The investigators found that when a dendritic cell (left; see Supplementary Movie 1 online) meets a target cell (right; DNA in blue and actin in red), the virus particles (green) scattered around the dendritic cell mobilize and cluster along the contact surface between the two cells. At the same time, HIV receptors also travel to the contact site. The flurry of activity at the interface enables some of the HIV particles to cross the divide into the target cell as shown here. The target cell in this image is a fibroblast transfected with the HIV receptor CD4 and its coreceptor CXCR4; the authors noted similar behavior using $T$ cells as the targets.

The authors propose that HIV takes advantage of the large surface area of dendritic cells to get as many particles taken up as possible and then concentrate them at the interface with the target cell, thereby increasing the chance of productive T-cell infection. Recent studies with other pathogens suggest that this exploitation may be fairly widespread, say the authors.

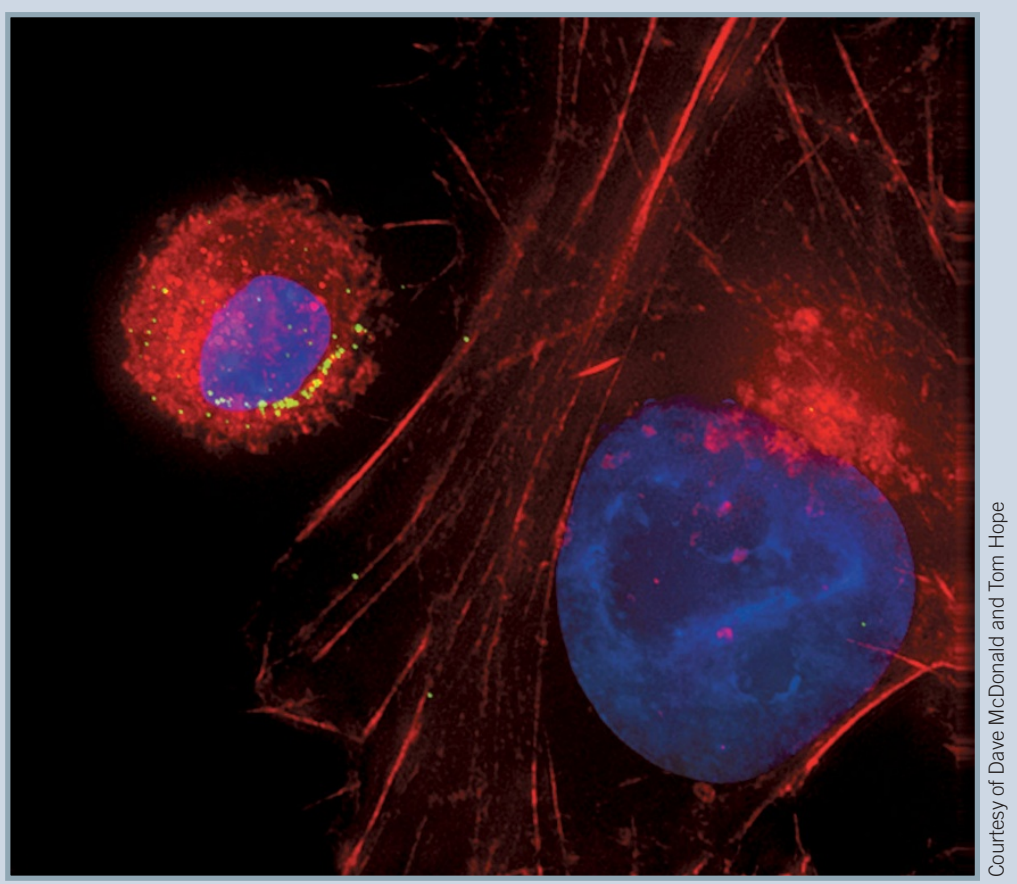

Pierrette Lo 